\title{
A PRODUÇÃO DA ESTRUTURA FUNDIÁRIA URBANA NO LITORAL NORTE DE JOÃO PESSOA E SUA IMPORTÂNCIA PARA A COMPREENSÃO DA SEGREGAÇÃO SOCIOESPACIAL
}

\author{
João Manoel de Vasconcelos Filho \\ Professor do Departamento de Geografia da Universidade Federal do Rio Grande \\ do Norte, Campus Caicó.
}

\section{Resumo}

O processo histórico da produção da estrutura fundiária urbana no litoral norte de João Pessoa revela várias contradições. Nesse sentido, a discussão preocupa-se em abordar a construção da renda fundiária urbana, suas relações complexas e as intermediações dos promotores imobiliários e o Estado. Num outro momento, faz-se um levantamento no espaço-tempo da projeção desta estrutura fundiária salientando os atores e agentes participantes desse processo. O objetivo desse texto é não apenas abordar o modelo de projeção da estrutura fundiária urbana na porção litorânea norte de João Pessoa, mas também discutir sobre as contradições reveladas a partir da aquisição da renda fundiária que a terra urbana passa a proporcionar para aqueles atores e agentes que participam de forma ativa do sistema produtivo. Sob este aspecto, discute-se também a falta de compromisso do Estado, bem como a segregação socioespacial, que transforma a cidade em uma rara mercadoria destinada a poucos.

Palavras-Chaves: Estrutura Fundiária Urbana. Segregação Socioespacial. Litoral Norte de João Pessoa

\begin{abstract}
The historical production process of the structure urban in the north coast of Joao Pessoa reveals several contradictions. Accordingly, the discussion focuses on addressing the construction of income urban land, their complex relationships and the hook of property developers and State. In another moment, we do a survey of the space-time projection of the land structure, highlighting the agents and participants in this process. The goal here is not only addressing the projection model of the structure of urban land in the coastal portion north of Joao Pessoa, but also discuss the contradictions revealed through the acquisition of the rent that urban land provides for those actors and agents who participate actively in the production system. In this regard, we discuss also the lack of commitment of the State and spatial segregation, which transforms the city into a rare commodity for a few.
\end{abstract}

Keywords: Structure of the Urban Land. Spatial Segregation.

North Coast of Joao Pessoa. 


\section{Introdução}

O espaço e o tempo são testemunhos da construção e da projeção de uma estrutura fundiária que, desde seus primórdios, criaram as condições ideais para as classes sociais de alta renda se beneficiar da terra, fazendo desta, uma fonte inesgotável de renda, neste caso, da renda terra urbana.

Sabe-se que por volta de 1850 a terra passou a ser comercializada como qualquer outra mercadoria. Entretanto, antes mesmo de se tornar produto do capital, a terra adquirida por doações, sesmarias e outras formas de aquisição, era destinada aos que possuíam o título de nobreza, ou mesmo os que faziam parte de um ciclo de beneficiados, recebiam a terra para seu uso fruto. Já se criava, portanto, o processo de segregação socioespacial que, posteriormente estabelecido, produziu as compartimentações e estratificações sociais espacializadas.

Sob este aspecto é lícito afirmar que o espaço-tempo em que foram projetadas e materializadas no espaço urbano da cidade a estrutura fundiária pode ser considerada como um importante referencial da espacialidade da pobreza urbana, que no momento atual, ganhou, não apenas velocidade, mas também novas e complexas formas de produzirse e reproduzir-se cotidianamente. Sendo assim, é gerado um movimento cíclico e vicioso de uma estrutura fundiária urbana segregadora e segregante, pois que torna a cidade um “jogo de cartas marcadas”. Sob esta perspectiva, é sempre ganhador aquele que detém o poder vinculado às artimanhas do capital.

A produção e reprodução de um modelo maléfico da espacialidade da pobreza urbana são alimentadas constantemente por esta forma maquiavélica da estrutura fundiária urbana. É interessante salientar que ela não só se concretiza na paisagem da cidade, mas gera, faz nascer conflitos, violência e morte.

Apesar de tudo, percebe-se o desinteresse do Estado de estabelecer as condições reais e necessárias de políticas públicas para atenuar a questão em tela. A sociedade já percebeu que em meio a tudo isto o que se tem visto é uma "maquiagem" da estrutura fundiária urbana, que de fato não consegue mudar a realidade das cidades, por conseguinte, a sua estrutura social. Para esta mudança ocorrer é preciso observar a concentração econômica em determinados espaços, que faz ressurgir, a cada instante, o que já se conhece como desenvolvimento geograficamente desigual. As diversas regiões do território brasileiro, percebe e vivencia esta problemática, daí porque as correntes migratórias regionais tem sido constante, embora seu ritmo tenha diminuído. É finalmente na cidade que a estrutura fundiária urbana se reproduz com os mesmos traços do passado, ou seja, sem que nenhuma mudança efetiva ocorra. A cidade deve ser usufruída por toda a sociedade, não apenas por uma pequena parcela de privilegiados.

\section{Algumas considerações sobre a produção da renda fundiária da terra urbana}

A discussão da estrutura fundiária urbana leva-nos a refletir sobre a questão da renda fundiária. Nesse caso, a leitura e interpretação marxista de teóricos como Christian Topalov (1979) e Jean Lojkine (1979) nos oferece uma análise mais atual das interpretações de Marx no tocante à renda fundiária, em especial da renda fundiária urbana Trabalharemos também com as discussões elaboradas por Paul Singer (1978). Nesse sentido, estes autores reconhecem três tipos de renda fundiária, quais sejam: a renda diferencial, a renda absoluta e a renda de monopólio. A título de esclarecimento, Lojkine apesar de reconhecer três tipos de renda fundiária, utiliza as denominações: renda diferencial I, renda diferencial II e renda absoluta. 
De acordo com Lojkine (1979), a criação de uma renda fundiária urbana está ligada não apenas aos agentes promotores do espaço urbano, como por exemplo: os empresários da construção civil e do mercado imobiliário, mas também aos grupos hegemônicos dos mais variados setores da economia, que passam a exercer a função de agentes financiadores. Nesse contexto, o autor explica: “O novo proprietário fundiário do estágio monopolista é o empresário financiado pelos grandes grupos monopolistas -, que utiliza o espaço urbano como uma fonte de sobrelucro" (LOJKINE, 1979, p.89-90). Ainda sobre esse aspecto este autor reforça a afirmativa quando diz:

Restam, pois os casos onde as relações entre proprietário fundiário e construtora vinculam-se com os agentes que não pertencem à esfera do capital produtivo, mas à esfera da circulação do capital - centros de distribuição comercial, estabelecimentos financeiros, escritórios, sedes centrais de empresas não diretamente ligadas à produção industrial, administrações públicas... (Ibid., p. 84).

De acordo com Jean Lojkine (1979), para existir uma renda fundiária é preciso duas condições: A primeira condição diz que a composição do capital investido deve ser menor do que a média social do capital. Em outras palavras, o valor despendido para a produção deve ser inferior ao valor dos produtos obtidos. Mas o autor adverte: Esta condição não é, no entanto, suficiente: "Ela não impede que o sobrelucro seja eliminado pelo livre jogo da concorrência isto é, da livre circulação de capital entre esferas econômicas” (Ibid., p. 81).

A segunda condição, que seria aquela que definiria com mais firmeza a existência dessa renda fundiária é atribuída ao que o autor denomina de obstáculo, entendido aqui como a monopolização da propriedade privada da terra por um determinado grupo social. É preciso esclarecer que, de acordo com reflexão de Lojkine (1979) estas condições estão em suas origens no setor de terras agrícolas, mas que transcendem para o âmbito do solo urbano, com algumas variações.

Nesse contexto, trazendo essa discussão para a especificidade desse estudo, entendemos que a renda fundiária urbana existe, embora se devam considerar suas particularidades e mutações que a distanciam de uma terra agrícola. Sobre esse tema o autor pergunta se de fato existe uma renda fundiária urbana:

a) A renda fundiária urbana existe no nível da construção civil (de imóveis) em terrenos com este fim[...].

b) A renda fundiária urbana existe, mas sob uma forma desvirtuada pouco importante, na relação entre proprietário de imóveis residenciais e seus ocupantes não capitalistas (locatários ou co-proprietários submetidos ao aluguel-venda) (Ibid., p.82).

Ao nosso ver, é bastante oportuna a reflexão deste autor, no momento em que ele coloca de forma transparente que a renda fundiária urbana passa a existir de fato na construção civil de imóveis e nas relações constituídas entre o proprietário privado desses imóveis e outros setores da cadeia produtiva, envolvendo agentes que não estão ligados diretamente ao mercado de imóveis, mas que dão suporte a estes.

Com efeito, percebemos também que alguns aspectos inerentes aos imóveis como, por exemplo: a localização, a escassez, os custos de transportes, infraestrutura e outros, possuem uma clara influência na composição do valor da renda fundiária urbana. 
No tocante ao litoral norte de João Pessoa, a localização e a escassez são dois elementos importantes na contribuição da elevação do preço do solo urbano, como também dos imóveis construídos. Já dissemos anteriormente que a terra urbana litorânea vem se tornando cada vez mais escassa, principalmente, na porção que está sendo investigada.

Tanto para Topalov (1979), quanto para Paul Singer (1978), a renda diferencial, vista essencialmente sob o aspecto do processo de produção do espaço urbano, está diretamente ligada à questão da localização. Sendo assim, as áreas mais bem localizadas da cidade irão proporcionar aos seus proprietários uma renda maior do que aquelas situadas na periferia, por exemplo.

Com efeito, remetendo este assunto para a área de estudo, podemos afirmar que, sem sombra de dúvidas, todos os imóveis localizados nos bairros litorâneos possuem preços mais elevados em relação ao conjunto da cidade. Vale salientar que isso ocorre mesmo com os imóveis que estão próximos aos aglomerados subnormais. Nesse contexto, percebemos que o aspecto locacional para o presente estudo é enfático, sendo, portanto, 0 eixo fundamental, gerador de uma renda diferencial.

(...) Para produzir duas unidades habitacionais idênticas, do ponto de vista do valor de uso, o montante de capital que deve ser empregado pelo empreiteiro é diferente segundo as localizações: para realizar a mesma operação, a soma do preço da produção das mercadorias particulares que a compõe variará; o empreendedor compara, segundo os terrenos, o "preço de custo construção mais equipamentos" a um valor de uso idêntico - a diferença desta grandeza, segundo as localizações, vai ser um primeiro componente da formação do preço no mercado de terrenos (TOPALOV 1979, p. 69).

Dessa forma, observamos de acordo com as colocações de Topalov (1979) que a base de sustentação da renda diferencial está na localização. Ao afirmar que os empreiteiros despendem somas diferentes em um valor de uso idêntico, entendido aqui, o uso para moradia e a diferença no custo da produção da unidade habitacional, resultam da localização do terreno, gerando o que o autor denomina de "sobrelucros de localização".

A renda diferencial atua, portanto, sobre a produção de imóveis construídos, levando em consideração a localização. 0 autor ainda coloca que a renda diferencial estaria nas condições de construbilidade reproduzíveis, ou seja, na produção de apartamentos e outros tipos de unidades habitacionais.

No tocante à renda absoluta, Topalov (1979) coloca que, a condição primordial para sua existência no âmbito da construção civil é o "terreno a construir", que apresenta duas características fundamentais, quais sejam: monopolizado por um determinado grupo social e não reproduzível. Desta forma o autor definiria este importante elemento constituidor de uma renda absoluta. "Compreende-se por terreno a construir uma fração de espaço, onde a produção de uma construção é possível e onde esta construção possa fornecer o valor de uso necessário a sua realização comercial" (Ibid., p.72).

A renda de monopólio pode constituir-se também a partir da implantação de infraestruturas, necessárias às condições de construção de moradias, que por sua vez, são empreendidas pela esfera pública. O proprietário desses imóveis se beneficiam, quando seus imóveis alcançam maior preço no mercado. 
Desse modo, entendemos que a renda absoluta atua sobre as condições não reproduzíveis de construbilidade, ou seja, sobre os terrenos a construir, bem como sobre o excedente gerado pela produção dos imóveis (casas e apartamentos). Por fim, a renda de monopólio no processo de construção civil está nas mãos de grandes empresas que realizam a construção de empreendimentos de grandes dimensões, como por exemplo: edifícios, grandes centros de compras, conjuntos habitacionais etc. A esse respeito o autor comenta:

As grandes construtoras estão em posição favorável para se beneficiarem destes sobrelucros. De um lado, o volume de seu capital produtivo e de sua produção permite-lhe produzir certas mercadorias a um preço de produção inferior ao das pequenas empresas. De outro, sendo as únicas capazes de realizar certas obras, elas podem se beneficiar de uma situação de monopólio sobre os mercados correspondentes (grandes conjuntos, grandes edifícios etc.) (Ibid., $p$. 69).

Já no dizer de Paul Singer (1978), a renda de monopólio resulta da utilização de uma determinada atividade, em uma dada área, que possui a exclusividade sobre o fornecimento de uma mercadoria que será comercializada. Desse modo o autor afirma:

Nestas condições, os que dispõem do monopólio, graças à localização podem cobrar preços mais elevados pelos produtos que vendem, o que dá lugar a uma renda de monopólio que é, em geral, apropriada no todo ou em parte pelo proprietário do imóvel (SINGER, 1978, p.26).

Este autor cita, entre outros exemplos, o caso das pessoas que têm lojas em shopping centers. Tais proprietários dispõem de monopólios de vendas de determinadas mercadorias. Por fim, o autor distingue a renda diferencial da renda de monopólio.

A renda diferencial é auferida quando as empresas que a pagam se encontram em mercados competitivos, sem que os produtos por elas vendidos sofram qualquer majoração de seus preços. A renda de monopólio porém surge do fato de que a localização privilegiada da empresa lhe permite cobrar preços acima dos que a concorrência normalmente forma no resto do mercado (Ibid., p. 27).

Esta complexa rede que podemos denominar de comércio de terras urbanas é um importante elemento da projeção da estrutura fundiária no espaço urbano. Topalov (1979) entende, no entanto, que a necessidade da existência de uma base para a reprodução do espaço construído é um dos obstáculos que o capital encontra para sua reprodução.

A produção de habitações, desde que desenvolva as relações de produção capitalistas, está subordinada a uma mesma lei e, no entanto, o processo de produção capitalista da habitação apresenta características tais que a reprodução das condições de acumulação encontram obstáculos específicos: por um lado, no que se refere ao período de rotação, por outro, no que se refere à base fundiária da produção (TOPALOV, 1979, p. 53). 
$\mathrm{Na}$ afirmação do autor, notamos que ele evidencia dois problemas que se traduzem como entraves para a reprodução capitalista no âmbito da produção de imóveis, quais sejam: o tempo de rotatividade do capital investido, e a necessidade, ou condição da existência de uma base material para a consolidação da construção de um imóvel.

Desse modo, Chistian Topalov (1979) explica que o processo de produção de um imóvel é longo, consequentemente, o retorno do capital investido em forma de dinheiro é lento. "O período de produção de um imóvel de habitação é longo, pois a entrega do produto final exige um processo de trabalho muito maior porque o valor de uso que ele resulta é divisível" (Ibid., p.54). No tocante à base fundiária, considerada um pré-requisito para que se processe a produção de imóveis, o autor explica que: "[...]A disponibilidade de um fluxo permanente de solo urbanizável é uma condição da acumulação ampliada na esfera da construção civil" (Ibid., p.59).

No entanto, é preciso lembrar que hoje, devido às inovações tecnológicas nos mais variados setores da economia e da vida na sociedade, esse tempo do qual se refere Topalov (1979), está cada vez mais suprimido. Não é à toa que Milton Santos (1999) lembra-nos também que vivemos o tempo da celeridade dos acontecimentos e que o mesmo ocorre em função do uso das mais modernas tecnologias, em todas as relações que se processam na sociedade.

É interessante observar na área que estamos desenvolvendo este estudo que, até a década de 1980 e início dos anos 90 era fácil se encontrar lotes vazios, prontos para construção. Tomando como referência as observações realizadas no local, as fotografias, e o levantamento dos objetos construídos durante as décadas de 80 e 90 , constatamos que existem poucas áreas para serem ocupadas, exceção feita à porção sul do bairro de Intermares que abriga uma considerável área já loteada e algumas áreas dispersas do bairro do Bessa.

Observamos que a reprodução deste espaço, que ocorre de forma acelerada, dá-se a partir da substituição de objetos construídos, principalmente, nos bairros de Cabo Branco, Tambaú e Manaíra. Constatamos ainda que há uma contínua substituição de residências unifamiliares por residências multifamiliares. Ocorrem ainda os casos de atribuição de novos usos às residências mais antigas, principalmente, na primeira rua da orla marítima. Estas vêm sendo transformadas em pousadas, hotéis, restaurantes, bares, boates etc.

Este aspecto tem caracterizado bem essa área. A escassez de imóveis (lotes) bem como a localização privilegiada que ela possui, torna-se um diferencial significativo que incide diretamente e contribui para um aumento no preço dos imóveis construídos ou não. Um imóvel, localizado em Tambaú e um outro no conjunto residencial Mangabeira com as mesmas condições de instalações e infraestrutura possuem preços diferenciados. A distinção de preço no mercado de imóveis ocorre porque um está localizado próximo à praia, o outro, não. A localização é, portanto, um gerador de aumento de preço dos imóveis. Sobre essa questão tem-se que:

Quase sempreapropriedade fundiária urbana édotada de certas benfeitorias - ela é desmatada, arruada, cercada enão poucas vezes construída-, que dá a impressão que seu valor resulta das inversões feitas nestas benfeitorias. Mas, na realidade, a influência de tais inversões sobre o "valor" do imóvel muitas vezes é negligenciável. Para perceber isso, basta lembrar que imóveis com as mesmas benfeitorias podem ter preços completamente diferentes, conforme sua localização (SINGER, op.cit, p. 22). 
Desse modo, percebemos que o valor da renda, especificamente de uma parcela do solo urbano, pode ser atribuído por vários parâmetros, tais como: a localização, a escassez, a infraestrutura, e a instalação de equipamentos sociais urbanos. Estes, contribuem em larga escala para um aumento do preço da terra urbana bem como de seu valor, interferindo também no processo de organização espacial da cidade.

\section{O processo histórico da projeção da estrutura fundiária urbana no litoral nor- te de João Pessoa: base para a compreensão da segregação socioespacial do momento atual}

A criação da estrutura fundiária urbana na porção litorânea em estudo, pode ter se iniciado com as primeiras doações de terras (sesmarias) realizadas durante o período imperial. Os historiadores que se debruçaram em estudar a fundação da cidade de João Pessoa comentam em seus trabalhos que as propriedades eram concedidas a grupos de senhores que tivessem títulos de nobreza. Pode-se assim, observar traços da apropriação privada da terra, tendo como monopólio dessa terra, uma elite local.

A título de exemplo podemos citar o bairro do Bessa, cujo nome foi emprestado de um português denominado Antônio Bessa, que recebeu uma sesmaria do imperador PedroII. É interessante essa observação que se volta ao tempo, no momento em que se apreende a perpetuação do processo de concentração de terras, nas mãos de um grupo dominante. Este processo atravessou os séculos, vindo a se consolidar no momento atual.

No entanto, sabemos que o processo de doação de terras foi sendo transformado quando esta terra passou a ser vendida, ou seja, comercializada como um produto, um bem. Porém, o que não mudou até os dias atuais é o seu monopólio que se encontra nas mãos de um grupo dominante. Ou seja, o acesso à terra continua sendo dado a algumas frações privilegiadas da sociedade. No caso da cidade nós poderíamos perguntar: quem possui as melhores localizações? Continua sendo aqueles grupos ou camadas de alta renda.

Até 1822 a distribuição de terras no Brasil era realizada pelo regime de sesmarias. Sem levar em conta a ocupação indígena, após o descobrimento, por graça de Deus, as terras passaram a "pertencer" ao monarca, o qual por este "Direito" fazia concessões de sesmarias (grandes extensões de terras) e doações de datas (lotes menores). Estas formas de atribuir terras, impunha obrigações para quem as recebia e, teoricamente, o não cumprimento de algumas obrigações fazia com que a terra fosse devolvida (devolutas). Em 1822, foram suspensas as concessões reais, e, desta data até 1850, a terra passou a pertencer a quem "quisesse" ocupá-la - melhor seria dizendo, pudesse ocupar. Até 1850 a terra não era uma mercadoria, não podia ser comprada ou vendida (RODRIGUES. 1994, p.17).

A estrutura fundiária é um tema bastante polêmico e também complexo. De acordo com Marx (1977), essa questão surge inicialmente no campo, e só posteriormente ela se projeta na cidade com a denominação de urbana. Dessa forma, apesar de guardar estreitas relações, em suas origens, com a questão fundiária que se processa no campo, a estrutura fundiária urbana que é construída na cidade conserva alguns aspectos bastante peculiares.

A estrutura fundiária urbana pode ser entendida como a base que é projetada e montada para receber a implantação de objetos em suas mais variadas formas bem como para fins diversos da sociedade, do capital, e de toda cadeia produtiva. Dessa forma, no processo de produção do espaço urbano, criam-se áreas destinadas à instalação de 
residências (vertical ou horizontal), comércios, serviços, indústrias etc. Percebe-se então que, tudo o quanto for implantado no solo urbano resulta de interações entre a sociedade, o capital e o trabalho. Sobre essa questão Paul Singer (1978), comenta:

Sendo a cidade uma imensa concentração de gente exercendo as mais diferentes atividades, é lógico que o solo urbano seja disputado por inúmeros usos. Esta disputa se pauta pelas regras do jogo capitalista, que se fundamenta na propriedade privada do solo, a qual - por isso e só por isso - proporciona renda e, em consequência é assemelhada ao capital (SINGER, 1978, p.27).

A terra urbana é, desse modo, criada para atender a fins diferenciados no que diz respeito ao conjunto da sociedade. Porém, devemos enfatizar que esta deveria ser criada, principalmente, para cumprir uma função social. Para os promotores imobiliários, no entanto, a finalidade primordial é extrair renda, lucro, mais-valia, contribuindo dessa maneira para a acumulação e concentração de capital. Desde que a terra passou a ter valor de mercado, ou seja, foi transformada em um produto do capital, consequentemente, sujeita a leis estabelecidas pelo modo de produção capitalista, os interesses capitalistas se distanciaram da função social que a propriedade urbana deveria ter. A terra, de uma maneira geral, passa a ser vista como uma mercadoria.

Como já foi, afırmado anteriormente, a estrutura fundiária nasce no campo e passa a ser também reproduzida na cidade. Contudo, tanto no campo quanto na cidade, quem possui as maiores e melhores porções de terras, sempre são aqueles grupos que estão no nível mais elevado do edifício social, detendo dessa maneira o controle das terras. Configura-se, dessa forma, o seu monopólio.

Portanto, pode-se considerar que, a formação da estrutura fundiária urbana, precisamente das cidades localizadas na periferia do capitalismo, está vinculada a uma série de questões reveladas no espaço urbano. O surgimento de espaços segregados na cidade é um dos muitos problemas que podemos constatar. No caso brasileiro, essa situação é agravada pela altíssima concentração de rendas que já se tornou uma marca característica de nossa sociedade.

No entanto, não é apenas o capital per si que constrói as contradições socioespaciais. 0 Estado é também um agente bastante representativo. A situação é agravada quando este deixa de cumprir suas funções sociais, principalmente no que diz respeito á questões primordiais como habitação, trabalho, fornecimento de água tratada, saneamento básico e energia elétrica. É incrível observar que no século atual, e mesmo nas capitais dos estados não tenhamos esses serviços para toda a população. Essa situação também é reproduzida em nossa área de estudo, principalmente no tocante ao sistema de esgotamento sanitário.

Com efeito, não podemos deixar de reconhecer, que os promotores imobiliários agindo em conjunto com a elite dominante local, somado ao apoio recebido pelo Estado, criaram uma forma de ampliar e concentrar capitais a partir da venda destes imóveis. Como toda mercadoria tem seu preço, a terra urbana passou a ser considerada um produto de alto custo a partir das novas relações que se estabeleciam entre o capital, o trabalho, e a sociedade. 
No caso específico do litoral, considerando a valorização que o próprio capital e a sociedade imprimiram às áreas litorâneas, o preço dos imóveis situados nesta porção da cidade aumentou significativamente, valorizando ainda mais os terrenos localizados não apenas nestas áreas, como também em suas proximidades.

Desse modo, a atuação dos agentes imobiliários incide no comércio de terras, numa operação que envolve compra, venda e troca de imóveis construídos ou não, pelos mais diferentes produtos. Dessa forma, são comercializados imóveis (lotes), apartamentos, residências unifamiliares, salas comerciais, escritórios, consultórios e outras modalidades de construção que servirão para os mais variados fins.

Por seu turno, o Estado, ao implantar as condições necessárias para o parcelamento das terras transformando-as em quadras e lotes, prepara o "terreno" para a ampliação desenfreada da malha urbana da cidade. No caso da área litorânea de João Pessoa esta ampliação como vimos foi direcionada para o norte do município.

Das operações imobiliárias pequenas aos grandes empreendimentos seguidas das cidades novas, a reprodutibilidade das condições urbanas de valorização do capital vão se estendendo: constatamos que este processo de socialização capitalista pressupõe a constituição de grupos imobiliários e de sua articulação com a ação do Estado em um "mecanismo único. (TOPALOV, 1979, p.59).

O projeto de montagem da estrutura fundiária urbana do litoral norte de João Pessoa vai se configurando com a transformação de antigos sítios ou propriedades rurais em imóveis urbanos. Tais propriedades foram distribuídas em parcelas. No caso em estudo, ocorreu sob a forma de loteamentos ou desmembramentos, que também são conhecidos como parcelamentos do solo. Assim, de uma propriedade única, geralmente pertencente a um só proprietário, a terra passa a ser dividida em quadras e lotes, que passarão a ser ocupadas por diferentes pessoas.

Estas áreas, como vimos, eram denominadas inicialmente de propriedades ou sítios, porque na verdade eram grandes porções de terras, que só foram adquirindo aspecto de terra urbana, quando a cidade de João Pessoa foi se expandindo em direção ao leste, ou seja, ao mar, incorporando, portanto, ao seu tecido urbano, aquelas propriedades. Realizase, dessa forma, o que se denomina de produção do espaço urbano. Sobre esse aspecto podemos nos apoiar nas palavras de Paul Singer (1978), quando ele afirma: 'A 'produção' de espaço urbano se dá em geral, pela incorporação à cidade de glebas que antes tinham uso agrícola" (SINGER, 1978, p.23).

Entretanto, no caso da área em estudo, tínhamos a coexistência de duas atividades primárias, talvez, complementares entre si. A pesca - utilizada como meio de manutenção das populações litorâneas (pescadores), e algumas culturas de subsistência, que também serviam para complementar a dieta alimentar dessas populações. A propriedade Tambaú e o sítio Cabo Branco estão nos relatos dos historiadores como áreas que tinham a finalidade agrícola.

Nesse contexto, de acordo com as informações colhidas junto ao setor de cadastro imobiliário da Prefeitura Municipal de João Pessoa, bem como nos cartórios Eunápio Torres e Carlos Ulysses nesta cidade, e o cartório Figueiredo Dornelas, em Cabedelo,a base para a produção do espaço urbano litorâneo pessoense, em sua porção norte, era constituída pelas propriedades Enseada do Cabo Branco e Tambaú, e pelos loteamentos São Gonçalo, 
Pan América, Jardim Oceania I, Jardim Oceania IV Jardim Bessamar, Pontal do Bessa I, Jardim América e mais recentemente Intermares, que tinha a denominação de fazenda Bela Vista, pertencente à família dos Garcia Ximenes.

No quadro 01 , organizamos alguns dados, como a localização do loteamento, a data em que o mesmo foi criado e a área total com o número de quadras e lotes. Assim, pudemos observar que as certidões obtidas nos cartórios não trazem todas as informações. Um esforço muito grande foi realizado para obter estes documentos, levando-nos, inclusive, a contratar um advogado para entrar com um mandato de segurança contra o cartório Eunápio Torres, que obstaculou o acesso aos registros desses imóveis.

\section{Quadro 01 - Levantamento da Base Fundiária da Área de Estudo}

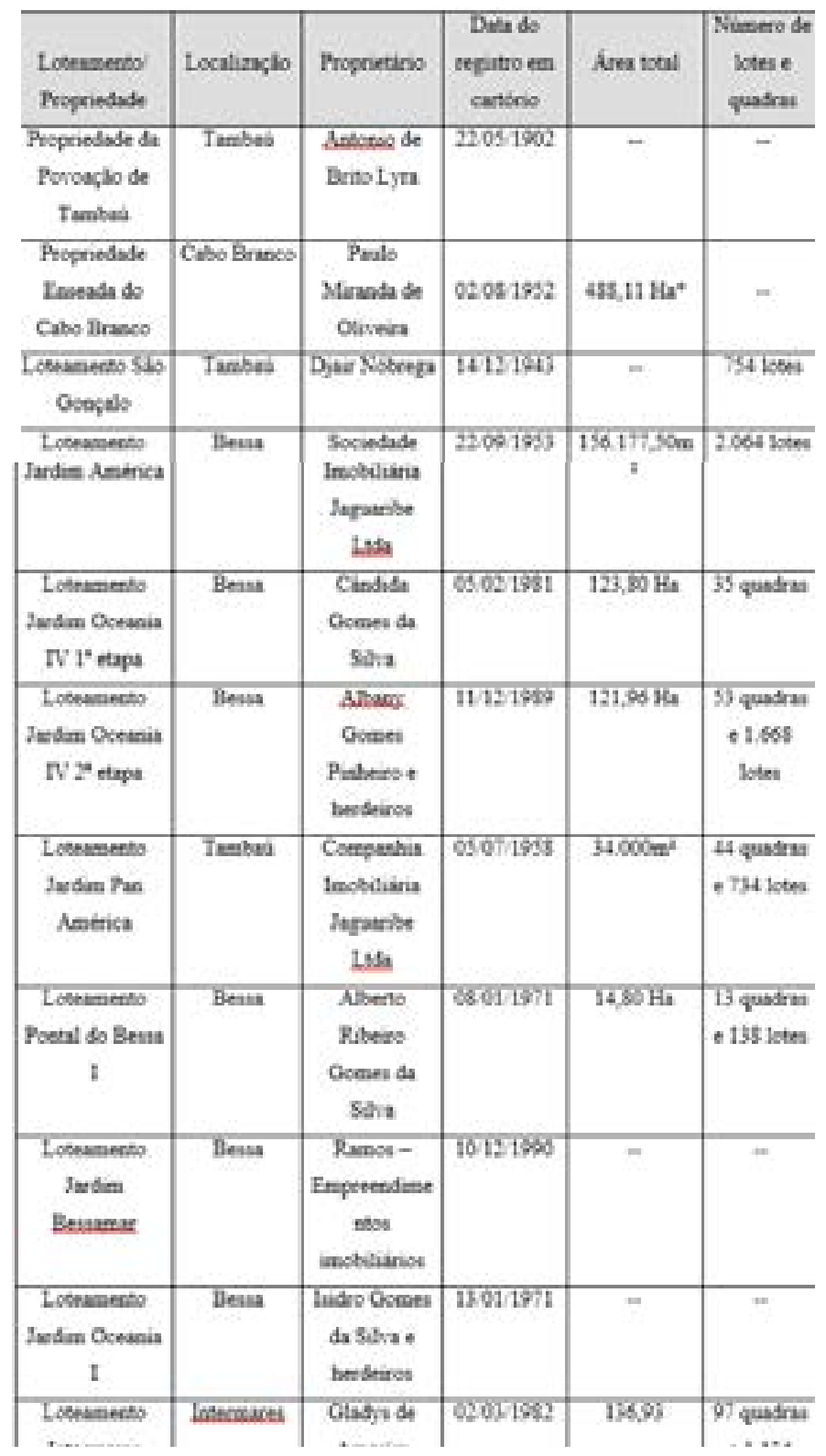

Fonte: Certidões de registros de imóveis e memoriais descritivos - cartórios: Eunápio Torres, Carlos Ulysses e Figueiredo Dornelas.

*Obs: A certidão de registro de imóveis da propriedade Enseada do Cabo Branco inclui também a Propriedade Timbó, atribuindo apenas uma área para as duas propriedades. 
As informações colhidas nos memoriais descritivos dos loteamentos foram cruciais para o entendimento do processo de produção do espaço urbano na porção litorânea norte de João Pessoa. Por exemplo, descobrimos que os loteamentos: Pontal do Bessa I, Jardim Oceania I e IV, pertenciam ao senhor Isidro Gomes da Silva, o que o tornava um latifundiário urbano. Este senhor possuía outras porções de terras que se situavam fora dos limites do nosso campo de estudo. Hoje, as áreas que pertenceram à família Gomes correspondem aos bairros do Bessa, Jardim Oceania e Aeroclube.

De acordo com o quadro 01 é possível observar que o conjunto da área de estudo é formado por nove loteamentos e duas propriedades. As propriedades mais antigas como a Povoação Tambaú, que data de 1902, e a Enseada do Cabo Branco, não foram transformadas em loteamentos como as demais descritas neste mesmo quadro. Sabemos, no entanto, por meio de um diálogo estabelecido com um antigo funcionário do cartório Carlos Ulysses, que a terra foi vendida pouco a pouco mas não foi registrada enquanto loteamento, no referido cartório.

Ainda de acordo com o quadro 01 (base fundiária), é possível constatar como é recente o processo de produção e reprodução do espaço urbano, essencialmente naquela área que envolve os bairros de Jardim Oceania, Aeroclube e Bessa, pois até a década de 1990 alguns loteamentos estavam em fase de implantação, como o Jardim Bessamar, por exemplo.

Todavia, é preciso esclarecer que, se por um lado o surgimento dessa área loteada é recente, sua ocupação vem ocorrendo de forma tão acelerada que já não se encontra com facilidade lotes à venda, isto talvez, seja mais visível no bairro de Intermares, onde foram abertas novas áreas, as quais denominamos de novas frentes de expansão urbana no litoral norte. Esse bairro se encontra localizado no município de Cabedelo, conferindo assim, a existência do processo de conurbação urbana.

Com efeito, vemos que a terra que foi transformada em urbana era monopolizada por algumas famílias tradicionais que faziam parte da elite local. É possível ainda demonstrar, que de acordo com o memorial descritivo do Loteamento Pontal do Bessa - I, juntamente com o Pontal do Bessa II, estes constituíam o lote 13 da antiga propriedade "Boi Só" ou "Ribamar". Estas, por sua vez, também pertenciam ao Sr. Isidro Gomes.

Todas essas áreas foram transformadas pelos agentes imobiliários, e ao invés da propriedade, sítio ou fazenda, implantou- se o loteamento. O solo passa adquirir características de urbano a partir da infraestrutura que vai sendo instalada, e também pelos novos usos e valores que vão sendo impressos. Isto ocorre em função da ampliação do território da cidade, que sugere novas áreas para serem construídas, não apenas para as residências, mas também para o comércio, serviços e outras atividades.

Com efeito, a ampliação territorial da cidade ocorre também de forma descontínua. O Estado mais uma vez é o grande parceiro dos proprietários privados da terra. Um bom exemplo é a implantação desses loteamentos que estão em evidência no quadro 01. Foram criados pelos seus proprietários com o aval das Prefeituras Municipais sem o mínimo de infraestrutura, mas valorizados a partir da instalação dos serviços e dos equipamentos urbanos cobrados a uma camada da população que se dirigia para a área, essencialmente, aquela porção que envolve os bairros setentrionais (Jardim Oceania, Aeroclube, Bessa e Intermares). 
Ainda que abriguem uma classe social de poder aquisitivo elevado, esses bairros carecem de uma melhor infraestrutura, principalmente, de saneamento básico, calçamento de ruas e drenagem das águas pluviais. Movido por financiamento adquirido através de convênios com a Caixa Econômica Federal e PRODETUR, os governos estaduais e municipais deram início ao programa de implantação dessas infraestruturas.

Nesse processo ocorre uma valorização dos terrenos, que agora contam com esses benefícios, e o que é mais importante, os proprietários desses imóveis não despenderam nem um gasto para isso, gerando dessa maneira uma especulação imobiliária, ou seja, o poder público utilizou recursos que foram pagos em impostos por uma coletividade, mas estes tributos foram destinados apenas a uma parcela da população, que foi desse modo, beneficiada.

Contudo, vale ressaltar que após as mudanças ocorridas na política econômica brasileira, a partir do início da década de 1990, principalmente sob o aspecto do processo de privatização, alguns desses serviços deixaram de ser públicos, como por exemplo: o fornecimento de energia elétrica e o sistema de telecomunicações, os quais passaram a ser controlados por grupos estrangeiros que atuam no mercado mundial. No entanto, há que se considerar que essa orientação de caráter neoliberal constitui uma imposição da atual conjuntura econômica de âmbito global.

Sendo assim, ao invés de encontrar meios para solucionar estas questões, o Estado brasileiro se desobriga de sua função social, aprofundando a problemática aqui discutida. Certamente, esse posicionamento tomado pelo Estado vai se refletir na vida das pessoas e na cidade.

Como vimos, o poder público não implantou de imediato as infraestruturas necessárias à ampliação dessa parte da cidade. Só depois da instalação dos equipamentos urbanos é que a esfera pública começou a instalar a rede de drenagem urbana, de saneamento básico, vias de acesso asfaltadas e iluminação. Mesmo assim, estes bairros cresceram com uma velocidade surpreendente. 0 que muda com essa infraestrutura é o índice de ocupação dessas áreas que passa a ser maior. Ou seja, pode-se construir mais numa área menor, sugerindo uma maior densidade urbana. Esta questão é de suma importância uma vez que vai contribuir para o processo de verticalização da cidade.

Isto demonstra que, ao se transformar em terra urbana, as antigas propriedades se sobrevalorizaram, havendo, portanto uma valorização do solo urbano litorâneo. Aqui fica claro a ocorrência de uma especulação imobiliária patrocinada pelos agentes imobiliários e pelos proprietários privados da terra urbana. Indica também que a cidade, na visão do capital é uma mercadoria bastante disputada e que a melhor parte é "dada", àqueles que podem pagar caro para obtê-la.

\section{Considerações Finais}

A construção da estrutura fundiária urbana que se projetou sobre a porção litorânea norte de João Pessoa, mostra desde os primórdios, uma clara divisão de classe. As doações de terras (sesmarias), e outras formas de distribuição, realizadas no período imperial, criavam os indícios de uma repartição de terra baseada em modelos segregatórios. Nesse período a terra, apesar de não ser vendida, já era dada àqueles que detinham o título de nobreza.

A doação de terra a um nobre português, denominado Antonio Bessa, é reveladora dessa segregação que se instituía. Até hoje a praia e o bairro recebem o sobrenome "Bessa". 
Se criava portanto, os referenciais de que este espaço seria destinado aqueles que detinham uma renda mais elevada. Embora, as contradições sociais geradas pelo modo de produção capitalista demonstrem que a porção litorânea em estudo abrigue classes sociais distintas, tendo como testemunho, os aglomerados subnormais.

Sendo assim, os documentos históricos e o levantamento dos registros dos imóveis realizado nos cartórios, evidenciam que as propriedades, sítios, fazendas e os primeiros loteamentos são de propriedades de famílias que compunham a elite local. Todo esse modelo de ocupação da terra, que mais tarde ganharia o signo do urbano testemunha e torna evidente uma espacialidade urbana segregadora, onde a divisão de classe não é apenas social, mas a um só tempo também espacial.

É por essa via que o processo histórico da constituição e da projeção da estrutura fundiária urbana ocorrida neste período serve de referência para a compreensão da segregação socioespacial que se consolida e se materializa no momento atual.

Nessa perspectiva é lícito afirmar que o litoral norte de João Pessoa é fortemente caracterizado por uma expressiva densidade urbana, o processo de reprodução do espaço urbano é, no mínimo, digno de registro, uma vez que observamos uma expansão urbana surpreendentemente acelerada e, ao mesmo tempo, reveladora de inúmeras contradições.

Soma-se a esse processo, o fato de que parte da população de classe média de João Pessoa tem manifestado o interesse de morar cada vez mais próximo ao mar. Reforçando esse aporte populacional, temos informações junto à imprensa local de que está havendo um deslocamento de pessoas de outros estados, tanto da região Nordeste, quanto de outras regiões do país. Segundo as entrevistas concedidas aos jornais locais, essas pessoas buscam a cidade de João Pessoa por acreditar que ela oferece uma relativa tranquilidade para se morar. Outros, todavia, buscam investir no setor imobiliário que se encontra em ascensão.

Desse modo, pudemos observar que, neste local há uma oferta expressiva de imóveis. Por outro lado, no tocante a lotes urbanos, a oferta não poderia ser significativa, uma vez que registramos poucas áreas para serem ocupadas.

A esse respeito, Cunha (1987) comenta que a onda crescente de escassez de terras conduz a um aumento do preço da terra urbana. Quando remetemos esta questão para o setor que estamos discutindo, a situação torna-se mais latente, justamente pelas especificidades que aqui já foram colocadas da terra urbana litorânea.

Nesse sentido, a localização, a acessibilidade e a escassez de lotes dos bairros estudados são, sem dúvida alguma, características importantes, no momento em que condicionam um aumento do preço, tanto do solo urbano quanto do imóvel construído. Como vimos, esta foi uma área que cresceu repentinamente e isto pode ser considerado um traço marcante das cidades latino-americanas, pois crescem sem a infraestrutura necessária. Daí porque surge toda ordem de distúrbios. 0 bairro do Bessa é bastante ilustrativo sob esse aspecto.

Dessa forma, constatamos que a acessibilidade foi socialmente produzida pela esfera pública. Contudo, observamos também que naquelas áreas mais carentes ou próximos a estas, o problema é ainda mais dramático e muito pouco tem sido feito para amenizar a situação das populações de baixa renda que residem, no caso deste estudo, às margens do rio Jaguaribe, ou mesmo nas encostas das falésias. Percebemos também que o Estado investiu primeiro naquelas áreas que em que os objetos já tinham sido instalados. Principalmente, aqueles de grande representação espacial, como os edifícios, os grandes equipamentos urbanos, a exemplo do Hiperbompreço e dos shoppings, dentre outros. 
Esse tipo de crescimento urbano, muito acelerado e desorganizado, é um traço comum das cidades que se encontram na periferia do capitalismo. Talvez, por isso, não possamos falar literalmente em um processo de urbanização, visto que este termo não se limita apenas ao surgimento da cidade e seu crescimento, mas é algo muito mais amplo, envolvendo todo um suporte de infraestruturas nos mais variados setores da sociedade e da cidade, influenciando em larga medida na qualidade de vida de seus moradores.

Com efeito, notamos que, as construções se realizam antes mesmo de haver a preparação da estrutura física da cidade. Sendo assim, a velocidade com que ocorrem as construções na cidade, resultando em um rápida ampliação do seu tecido urbano, é bem superior à implantação de um suporte necessário ao seu crescimento. Ainda podemos afirmar que, a incrível "onda" de objetos instalados, supera todas as diretrizes atribuídas no Plano Diretor.

No caso da área litorânea de João Pessoa que nos propusemos a estudar, este é um fato visivelmente observado. Uma outra característica dessa área é que, com raríssimas exceções, o que há de novo na cidade de João Pessoa, ocorre aqui, não é à toa que nos últimos vinte anos, este setor registrou os mais expressivos índices de construção para os mais variados fins, de toda a cidade, notadamente dos serviços e comércios. Inclusive, pode-se afirmar que a cidade vem assumindo um perfil vertical, a partir de sua porção litorânea norte.

Sendo assim, acreditamos que o estudo da estrutura fundiária urbana, não pode estar desvinculado do fato urbano, mesmo porque existem relações intrínsecas entre a estrutura fundiária que é montada na cidade e os objetos que são projetados sobre ela. Do mesmo modo, não poderíamos ter discutido estas questões sem o entendimento da renda diferencial assimilada como resultado das relações sociais de produção que se operam na cidade. Por fim, é preciso considerar a história e o modelo da estrutura fundiária urbana que se projetou neste espaço desde o momento inicial de sua ocupação.

\section{Referências}

CUNHA, Gelsonete Sotero. Natal: a expansão territorial urbana. Rio Claro: UNESP, 1987. Dissertação de Mestrado.

LOJKINE, Jean. Existe uma renda fundiária urbana? In: Marxismo e urbanismo capitalista. Textos críticos. Organizador: Reginaldo Forti. São Paulo: Livraria Editora Ciências Humanas, 1979.

MARX, Karl. Contribuição à crítica da economia política. Tradução de Maria Helena Barreiro Alves. São Paulo: Martins Fontes, 1977.

0 capital: Crítica da economia política: O processo de produção do capital. Tradução de Regis Barbosa e Flávio R. Kothe. São Paulo: Abril Cultural, 1983.

RODRIGUES, Arlete Moysés. Moradia nas cidades brasileiras. 5. ed. São Paulo: Contexto, 1994.

SANTOS, Milton. A natureza do espaço: técnica e tempo. Razão e emoção. 3. ed.São Paulo: Hucitec, 1999. 
SINGER, Paul. 0 uso do solo urbano na economia capitalista, 1978. In: A produção capitalista da casa e (da cidade) no Brasil industrial. Organizadora: Ermínia Maricato. 2. ed. São Paulo: Alfa ômega, 1982.

SAULE JÚNIOR, Nelson. ROLNIK, Raquel. Estatuto da Cidade: novas perspectivas para a reforma urbana. São Paulo: Pólis, 2001.

TOPALOV, Christian. Análise do ciclo de reprodução do capital investido na produção da indústria da construção civil: capital e propriedade fundiária. In: Marxismo e urbanismo capitalista. Textos críticos. Organizador: Reginaldo Forti. São Paulo: Livraria Editora Ciências Humanas, 1979.

\section{Observações}

I. O Estatuto da cidade, lei recentemente aprovada pelo Congresso Nacional, "é encarregada pela Constituição de definir o que significa cumprir a função social da cidade e da propriedade urbana, a nova lei delega esta tarefa aos municípios, oferecendo para as cidades um conjunto inovador de instrumentos de intervenção sobre seus territórios, além de uma nova concepção de planejamento e gestão urbanos" (ROLNIK, 2001, p. 5).

II. Para Marx (1983), "a mercadoria é, antes de tudo, um objeto externo, uma coisa, a qual pelas suas propriedades satisfaz necessidades humanas de qualquer espécie. A natureza dessas necessidades, se elas se originam do estômago ou da fantasia, não altera nada na coisa. Aqui também não se trata de como a coisa satisfaz a necessidade humana, se imediatamente, como meio de subsistência, isto é, objeto de consumo, ou se indiretamente, como meio de produção" (MARX, 1983, P. 45).

III. Na operação de promoção de imóveis estão envolvidas as construtoras, incorporadoras, corretoras de imóveis, e os agentes financeiros que podem ser as instituições bancárias ou grupos de empresários de outros setores produtivos. Por fim, temos a participação do Estado nas ações de implementação de infra-estruturas.

IV. A Lei de urbanização, que também recebe os nomes de Lei de parcelamento do solo, Lei Lehmann ou ainda Lei de Loteamentos, publicada no Diário Oficial da União sob nº 6.766, de 20 de Dezembro de 1979, atribui as seguintes considerações para parcelamento do solo urbano, loteamentos, desmembramentos e lotes. 0 artigo $2^{\circ}$ do capítulo I da referida lei define: "O parcelamento do solo urbano poderá ser feito mediante loteamento ou desmembramento, observadas as disposições desta lei e das legislações estaduais e municipais pertinentes". Já $\S 1^{\circ}$ do artigo $2^{\circ}$ relata que: "considera-se loteamento a subdivisão de gleba em lotes destinados à edificação, com abertura de novas vias de circulação, de logradouros públicos ou prolongamento, modificação ou ampliação das vias existentes." Enquanto o §2 do mesmo artigo diz que desmembramento "é a subdivisão de gleba em lotes destinados a edificação, com aproveitamento do sistema viário existente, desde que não implique na abertura de novas vias e logradouros públicos, nem no prolongamento, modificação ou ampliação dos já existentes." E finalmente o $\S 4^{\circ}$ considera "lote o terreno servido de infraestrutura básica cujas dimensões atendam aos índices urbanísticos definido pelo plano diretor ou lei municipal para a zona em que se situe." Este parágrafo, conforme a lei de urbanização diz que ele foi acrescentado pela lei no 9.785, de 29/011999, no DOU de 01/02/1999. (Texto eletrônico: Lei de urbanização, acessado em 22/08/2001) 
V. Para nós, o uso da terminologia litoral norte faz referência ao perímetro litorâneo, que tem início no bairro do Cabo Branco e termina no bairro do Bessa, acrescentando ainda o bairro de Intermares, que se encontra localizado no município de Cabedelo. Esta delimitação territorial compreende a área em estudo.

VI. O rio Jaguaribe é considerado o mais importante rio urbano da cidade de João Pessoa. Ele nasce em uma área denominada três lagoas, onde recentemente foi construído o viaduto, no entroncamento das BR-230 e 101. Nasce na porção sudoeste da cidade, percorrendo em direção NE até o limite dos bairros Cabo Branco e Miramar, tomando a partir deste ponto a direção N. Seu curso original foi desviado na década de 20 do século passado. Desaguava em dois pontos distintos, um nas proximidades do hotel Tambaú e outro entre os atuais bairros do Bessa e Intermares. Devido ao crescimento desestruturado da cidade, este importante fluxo hídrico teve suas margens ocupadas ilegalmente por dois grupos sociais distintos: os equipamentos urbanos de grande expressão como hipermercados, condomínios residenciais, o Manaíra Shopping, etc., e os aglomerados subnormais. 